\title{
دراسة حول السلوكيات الشائعة بين الأطفال
}

اعداد

الباحثة / نرمين أحمد الحناوى'

$$
\text { إشر افت }
$$

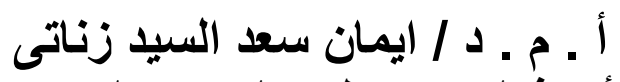

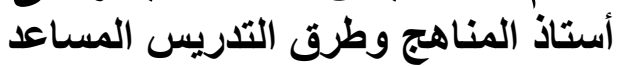

كلية التربية للطفولة المبكرة

جامعة القاهرة
أ ـ ـ الد / كمال الدين حسين محمد

أستاذ الأدب المسرحي والين والدين الدراسات

الثعبية كلية التربية للطقولة المبكرة

جامعة القاهرة

مقدمة

تعد مرحلة الطفولة عامة ومرحلة الطفولة المبكرة خاصة من أهم المراحل العمرية فى حياة

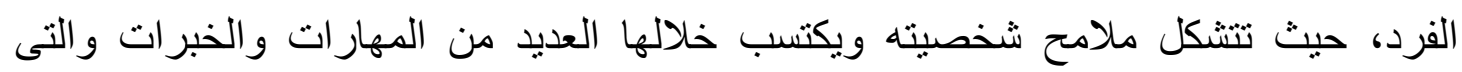

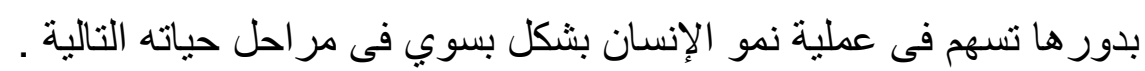

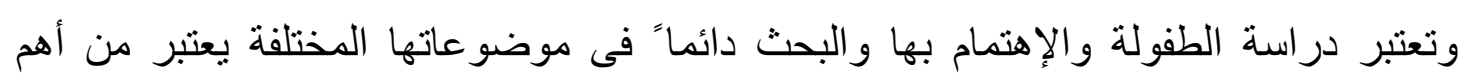

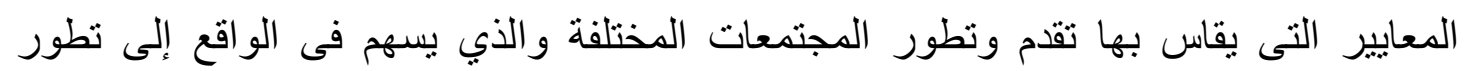
مستقبل الأمم . ولأن رعاية الطفولة والإهتمام بها يعد إهتماماً بمستقبل الأمة، لذلك ينبغي وضع رعاية شاملة

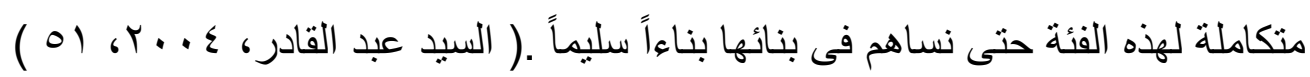

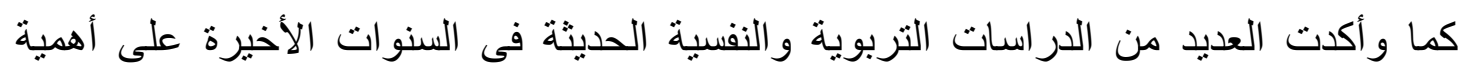

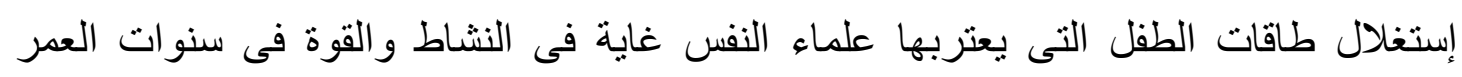
الأولى وجعل هذه الطاقات تصب فى دافع ومحرك ذهنى، الأمر الذى سينمى حتماً مهارات

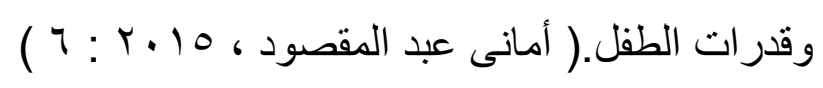

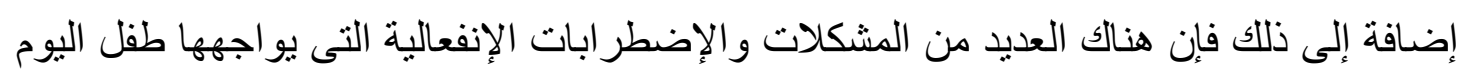

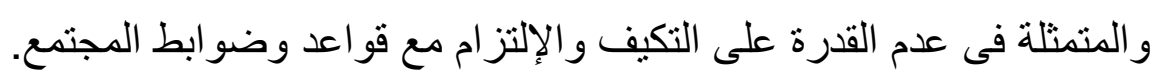

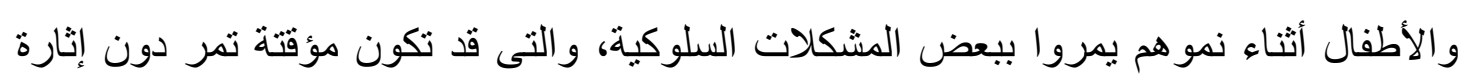

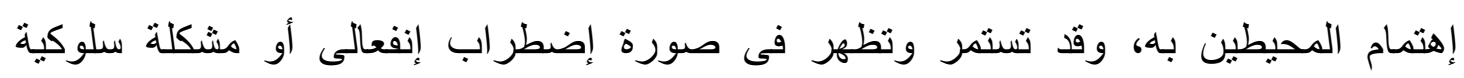

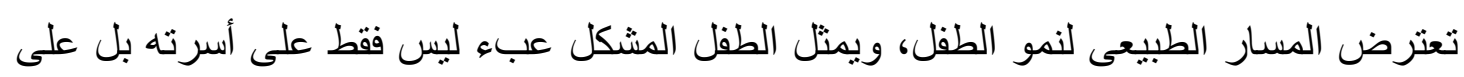

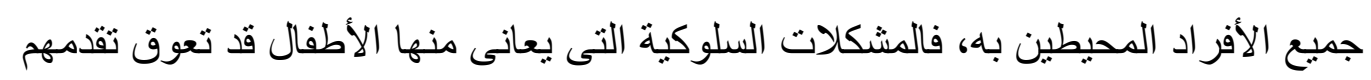


الدراسى وتحقيق أهدافهم فى الحياة، كما أنها تمثل مصدر إحباط للمدرسين وأولياء الأمور

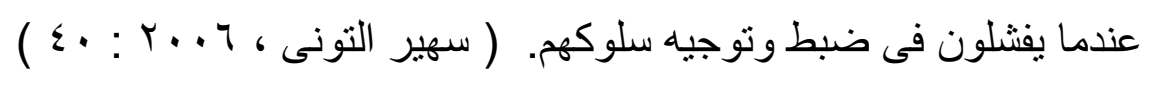
وتثؤثر المشكلات السلوكية على نواحى النمو المختلفة لدى الأطفال مما يحول دون نموهم

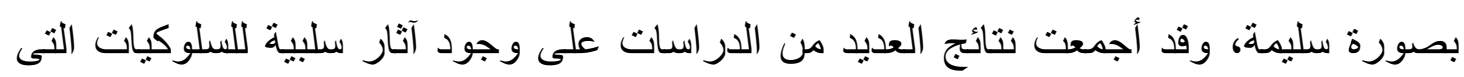
يمارسها الأطفال على نواحى نموهم الجسمى، والحركى، والإجتماعى، والإنفعالى، بالإضافة

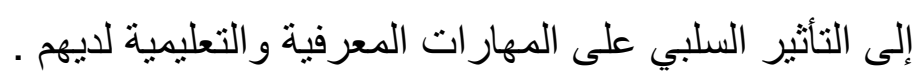

وحول حدوث وأسباب المشكلة السلوكية لدى الأطفال، إختلف الباحثون فى طريقة عرضهم

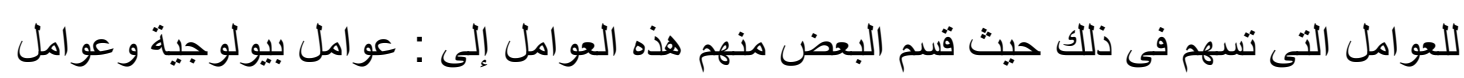

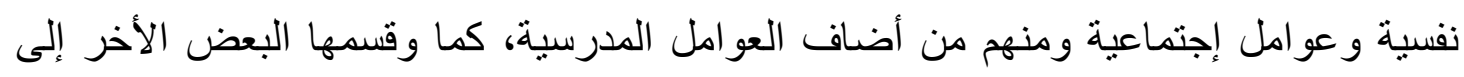

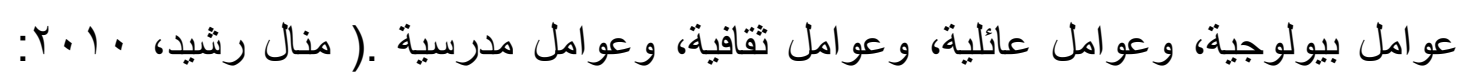
(Y) - 17 و هناك العديد من الدراسات والأبحاث التى تناولت وإستعرضت الأسباب المختلفة للمشكلات

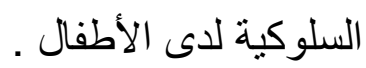

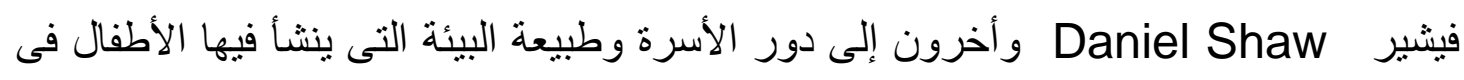

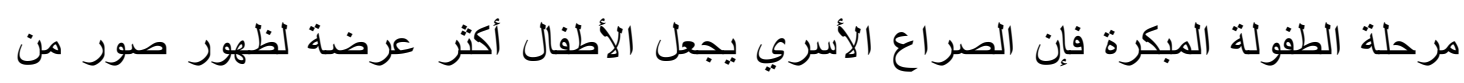

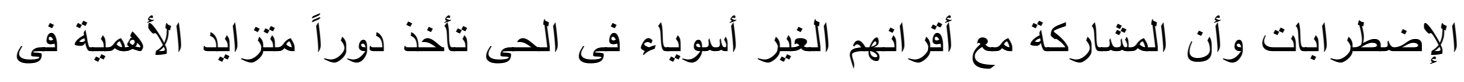

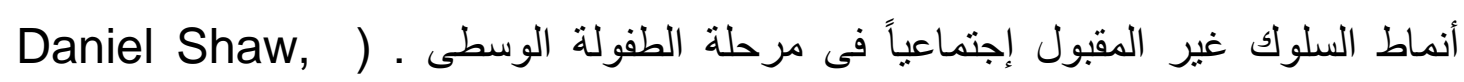
(2006: 19-303

وتضيف دراسة Michael Schonberg و أخرون إلى دور الأسرة وطبيعة البيئة التى يعيش فيها الأطفال فى مرحلة الطفولة المبكرة حيث أن الصراع الأسري يجعل الأطفال

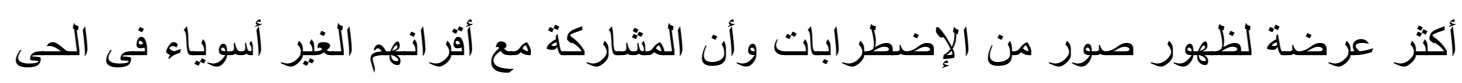

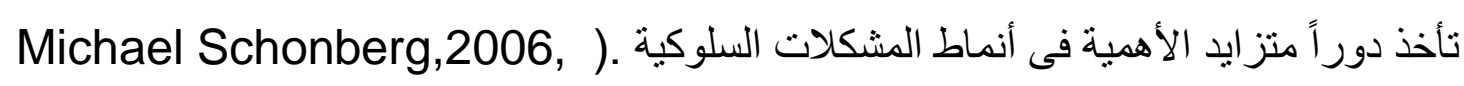

(293-309

ومما سبق وبالإطلاع على الإطار النظرى لبعض الدراسات ومن خلال عمل الباحثة كمعلمة رياض أطفال بإحدى المدارس الرسمية لاحظت تكرار مجموعة من الإطلار السلوكيات بين الأطفال بشكل شبه يومي والتى تثبر بدور ها لوجود مشكلات سلوكية لديهر. 
هذا إلى جانب الثكوى المتكررة من المعلمات تجاه بعض المشكلات السلوكية الثائعة بين الأطفال فى هذه المرحلة العرية و التى يو اجونها شكل ملحوظ فى الأونه الأخيرة . وبسؤال المعلمة لزميلاتها المعلمات من خلال ملاحظاتهم لأطفالهم داخل وخارج القاعة ومتابعة وملاحظة أطفال الروضة فى أوقات الراحة فى الملعب وطريقة لعبهم مع بعضهم البعض فوجدت أن هناك مجموعة من المشكلات السلوكية الثائعة بين الأطفال فى هذه المرحلة .

\section{مشكعة الدراسة : مئة}

ومما سبق وبالإطلاع على الإطار النظرى لبعض الدر اسات و الأبحاث ومن خلال عمل الباحثة فى إحدى المدارس الرسمية للغات محافظة القاهرة . فوجدت أن هنالك فئة من الأطفال مرحلة الطفولة المبكرة لديهم بعض المشكلات السلوكية والتى تظهر قوتها وحدتها على غير السلوك المشكل المعتاد بين بعض الأطفال فى مثل هذه المرحلة و التى تظهر فى صور مختلفة من ( العدوان - العناد - تشتت الإنتباه - التمرد - الكذب -

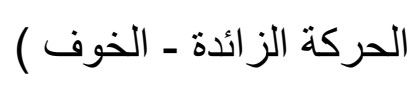

فى ضوء ما سبق تتبلور مشكلة الدراسة الحالية فى التساؤلات الأتية ما أشكال ومظاهر المشكلات السلوكية الثنائعة بين الأطفال ؟ ما أسباب المشكلات السلوكية الثائعة بين الأطفال ؟

\section{منهج الدراسة : من}

تتبع الدر اسة الحالية المنهج الوصفى والذى يعتمد على وصف وتحليل المعلومات للوصول إلى الأهداف المطلوبة من الدر اسة

\section{المشكلاث السلوكية :}

قبل البدء بتعريف المشكلات السلوكية فلابد من الإشارة إلى أن هناك العديد من التعريفات المختلفة للمشكلات السلوكية والتى تختلف وتتنوع طبقاً لوجهة نظر الباحث فى المشكلات 


\section{أولاً تعريف المشكلات السلوكية :}

وتعرفها إيمان صقر ( r ( ب ) بأنها الأنماط السلوكية التى تدل على وجود المشاكل، وتتعكس أثارها على الأطفال أو على من حولهم، ويعد هذا السلوك مخالفاً للمعايير المتعارف عليها داخل داخل المجتمع .

سلوكيات مختلفة يقوم بها بعض الأطفال بطريقة مختلفة عن الأطفال الذين فى سنهم وبشكل لا

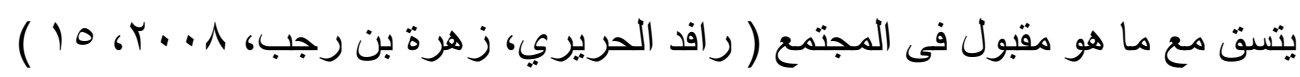

وتعرفها ليلي و افى بأنها جملة من السلوكيات اللا نو افقية التى بسعى المقياس المستخدم فى

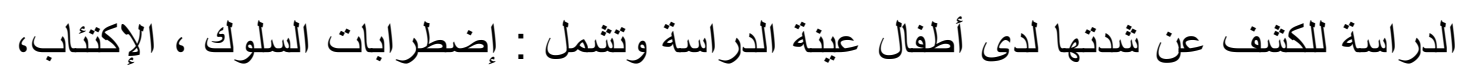

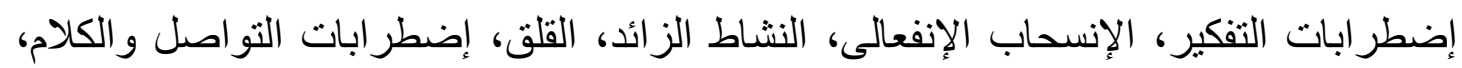

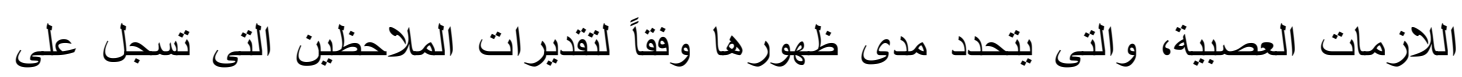

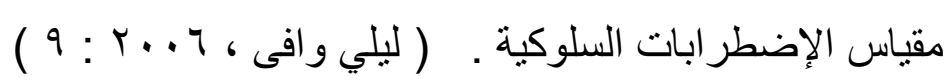

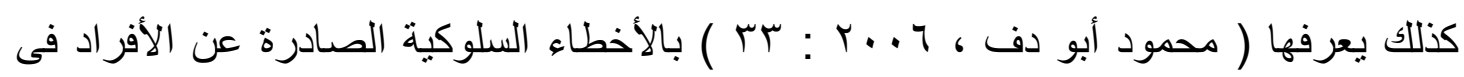

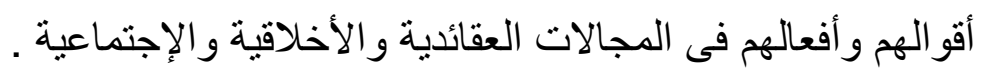

مما سبق يتضح أن المشكلات السلوكية هى مجموعة من التصرفات والأفعال غير المرغوبة التى تصدر عن الطفل بصفة متكررة و التى تتعكس على كفاءة الطفل الإجتماعية والنفسية ولا

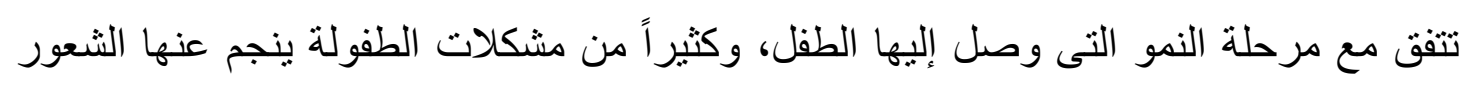

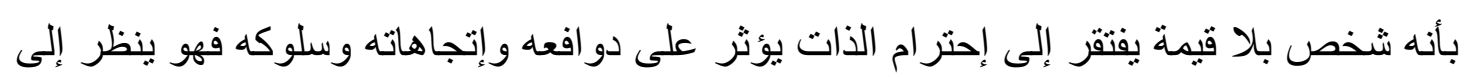
كل شىء بنظرة تنثاؤمية . إلى جانب ذلك فإن هنالك العديد من الدراسات التى تتاولت المشكلات السلوكية بجو انبها و أبعادها المختلفة حيث

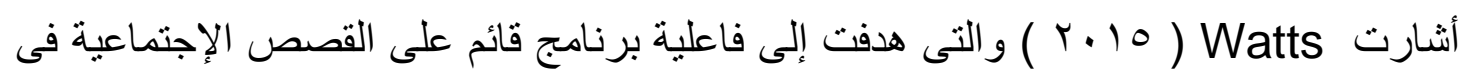

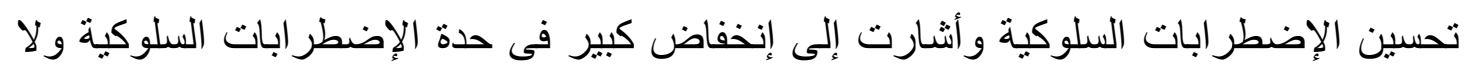
سيما العدو انية و التمرد و المعارضة لاى الأطفال عينة الدراسة. 


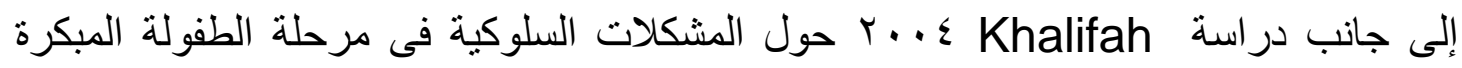
كأحد علامات نشتت الإنتباه والنشاط الزائد وأظهرت النتائج إرتفاع معدلات أعراض اضل النشاط

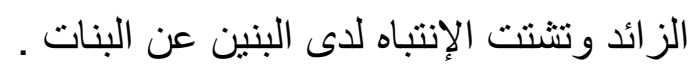

\section{ثانياً أسباب المشكلات السلوكية :}

دراسة الأسباب والعوامل التى تكمن وراء السلوك الإنسانى بصفة عامة تمثل أحد المهام الصعبة فى مجال علم النفس، حيث يرجع سبب ذللك إلى تعدد وتباين العوامل المسببة للظاهرة السلوكية الواحدة وإن تلاك الأسباب تتمثل فى الأتى :

\section{ا. العوامل البيولوجية:}

الور اثة : وهى التى يولد بها الطفل

وتتمثل فى شذوذ الجينات الور اثية .

إضطر اب وظيفة الدماغ بسبب نقص نضج الجهاز العصبي .

إصابة الأم خلال فترة الحمل بالأمر اض أو تناولها بعض العقاقير أو الكحوليات

\section{r. - العوامل النفسية:}

• الجو الإنفعالى العائلي : الثجار المتكرر بين الوالدين يدمر إتزان الطفل

الإنفعالى . الإنو

إضطر اب علاقة الطفل بكل من الوالدين : وتتمثل فى تفضيل أحد الأبناء عن

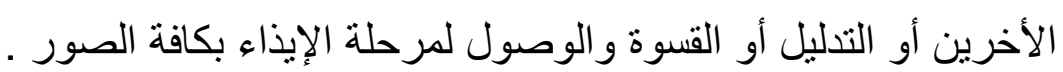

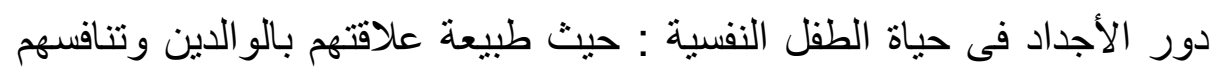

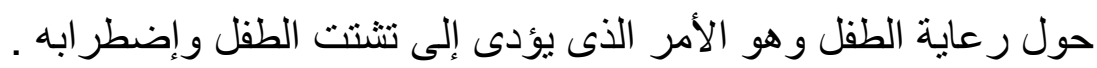

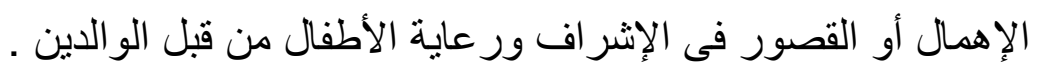

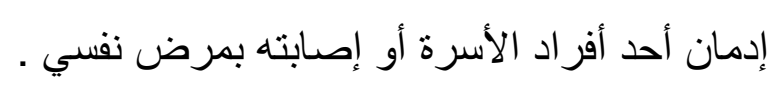

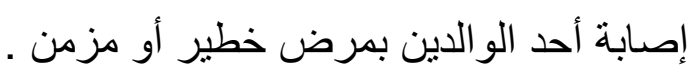

الحرمان : يتمثل فى عزل الصغير لفترة طويلة وإجباره على عدم الحركة .

ويمكن القول بأن إساءة معاملة الطفل تتمثل فى نظرة الو الدين السلبية للطفل

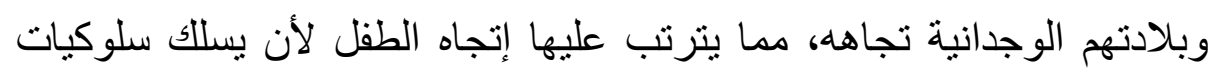

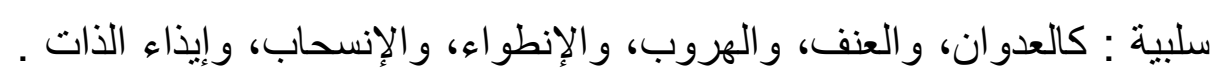

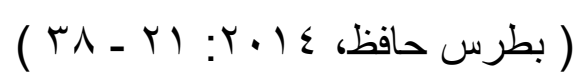


وتعتبر علاقة الطفل بو الديه من أقوى العلاقات فى حياة الطفل فهو منذ مولده لا يجد فى مجاله

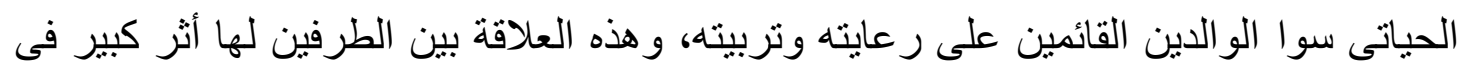

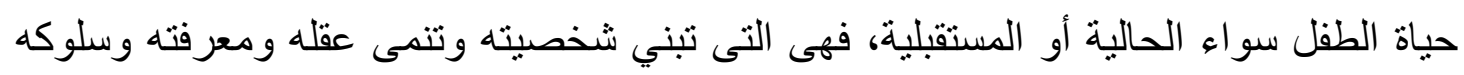

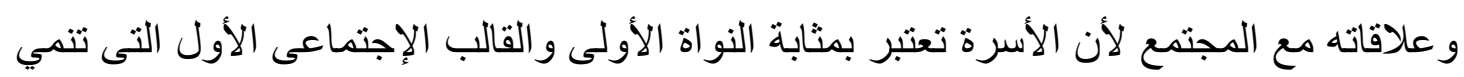
شخصية الطفل فى المجتمع وتساعده على تشكيل شخصيته بصفة عامة .

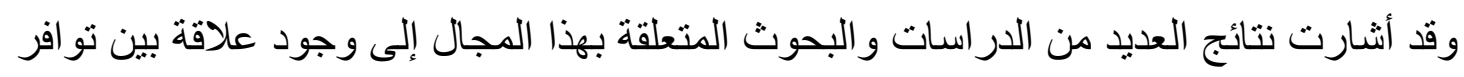
Mireault, et ) العوامل النفسية وظهور العديد من المشكلات السلوكية لدى الأطفال فقد فأل

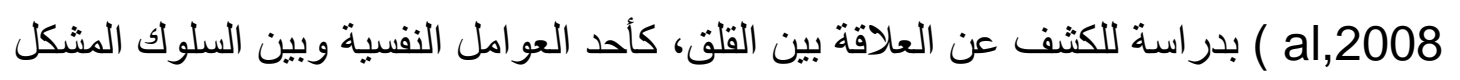

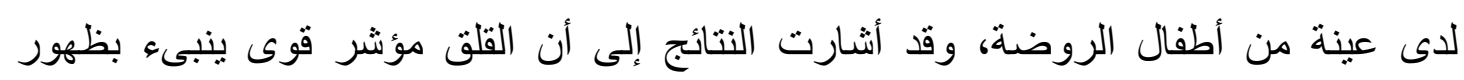

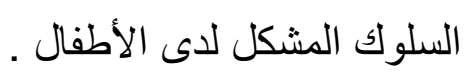

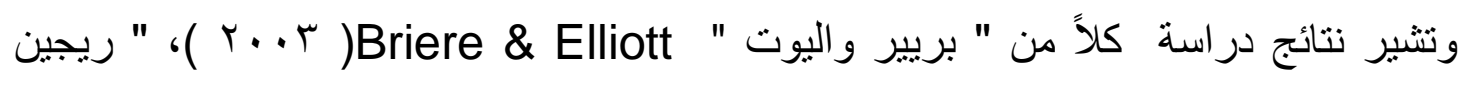

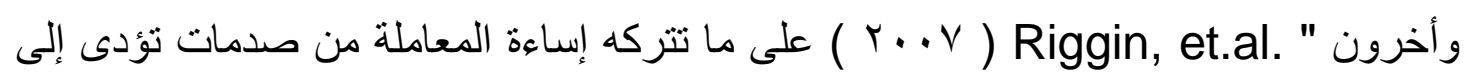

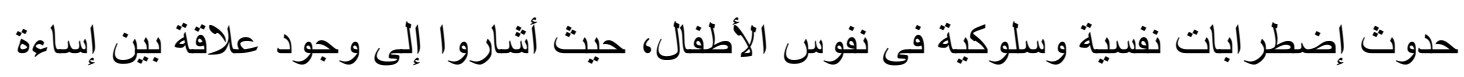
المعاملة وسلوك الطفل للسلوك العدوانى وتميزه بالمقاومة والعناد، بل ورغبته فى إيذاء الذات التهات وشعوره بالضيق و الحزن .

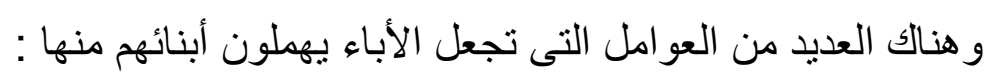

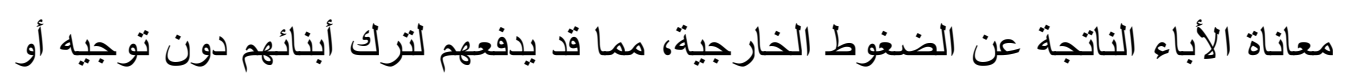
رعاية .

الخلافات الزوجية بين الأب والأم مما قد يجعل الأب يهمل أطفاله، ويحمل الأم مسئولية

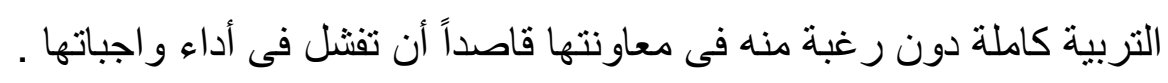
إنشغال الو الدين أو غيابهم المستمر عن الأبناء . تقصير الوالدين أو القائين على رعاية الطفل فى تلبية الإحتياجات البدنية أو الوجدانية

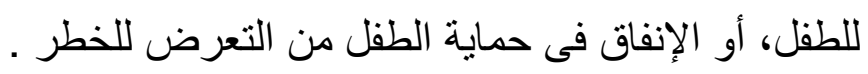

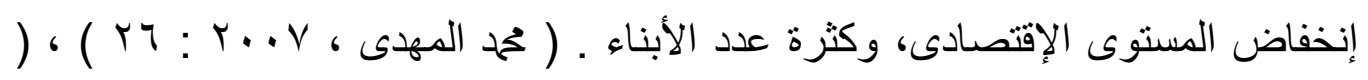

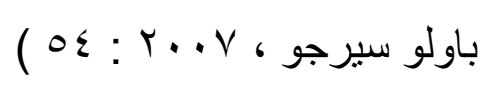
و أكدت على هذا دراسة جمال عطيه فايد ( V . . . ) و التى هدفت إلى معرفة مدى العلاقة بين أساليب المعاملة والو الدية وكل من خصائص مزاج الأطفال ومشكلاتهم السلوكية، وإمكانية إستخدام هذه المتغير ات فى التنبوء بالمشكلات السلوكية . 
للالك فإن سوء العلاقة بين الزوجين فككثير من الأحيان يؤدى إلى ممارسة سلوكية غير سوية وتفاعلات سلبية مما قد يساعد ويزيد من نمو و إستمر ار المشكلات السلوكية لدى الأطفال .

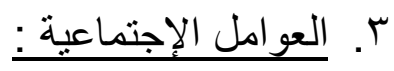

الفقر وسوء التغذية : يتمثل فى عدم قدرة الأسرة على توفير الغذاء الكافى

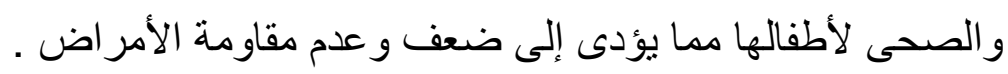

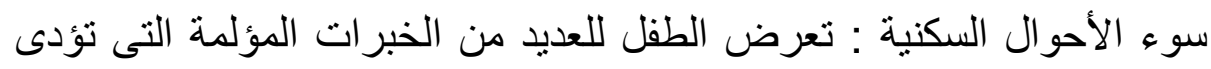

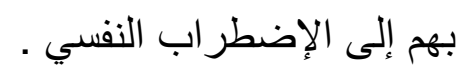

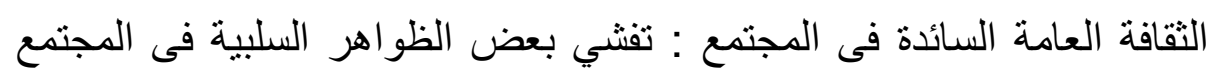
تؤثر بالضرورة فى سلوكيات الطفل .

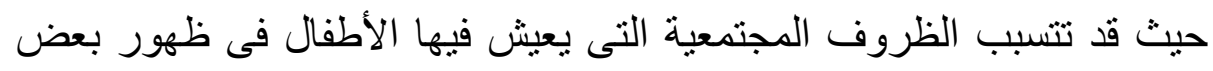

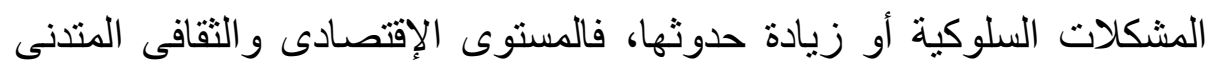
يؤديان إلى الحرمان من المثيرات الكافية التى تساعد على النضج النفسي

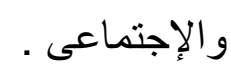

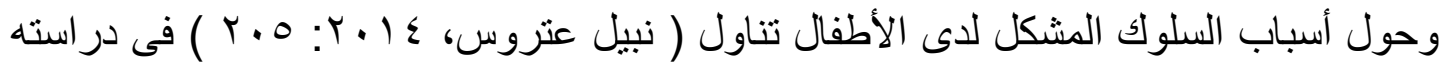
أن السلوك المشكل الذى يأتى به الطفل هو نتيجة للتفاعل الذى يحدث بين الطفل والبيئة

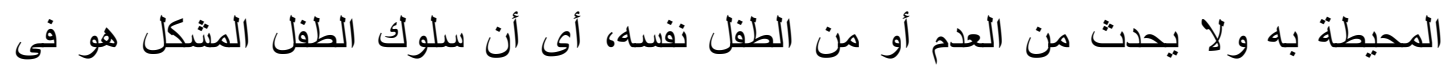

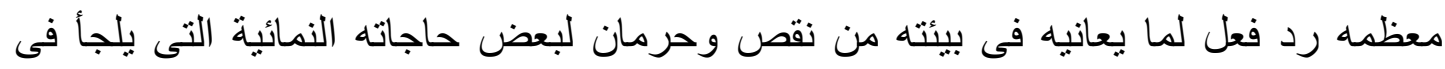

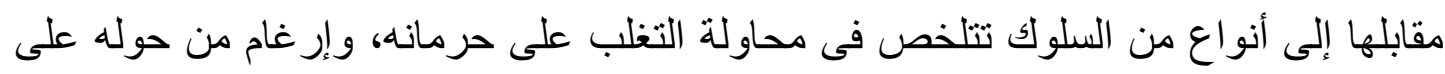
إثباع حاجاته الأساسية المختلفة، الأمر الذى يجعل الطفل يسلك بلى بالطريقة التى يعتقد أنها

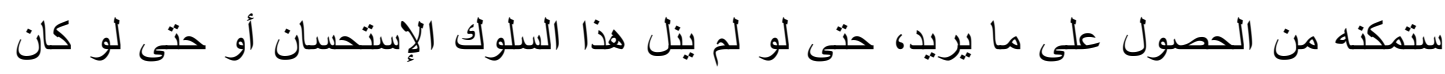
سلوكه هذا مؤذياً لغيره .

وسائل الإعلام وتعظيم القيم السلبية : حيث معالجة وسائل الإعلام لبعض

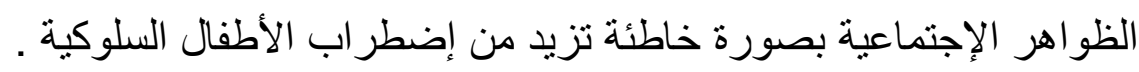

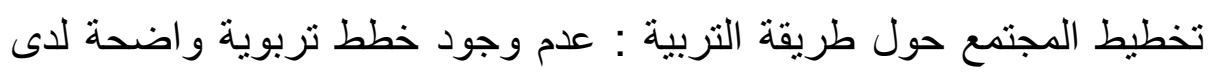
مؤسسات التنشئة الإجتماعية يؤدى إلى إختلال المفاهيم والقيم السائدة فى لى

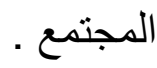

و هذا يتفق ودراسة (Shivers, 2003 ) والذى أكد على العلاقة بين معدل إكتئاب الأم والأسلوب الأسري ودوره فى زيادة المشكلات السلوكية لاى الطفل. 


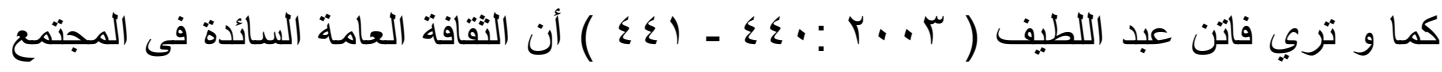

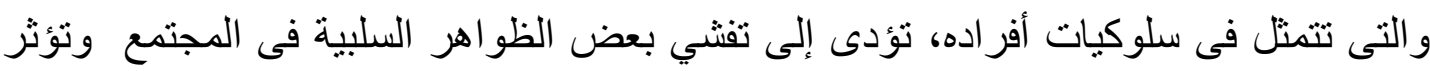

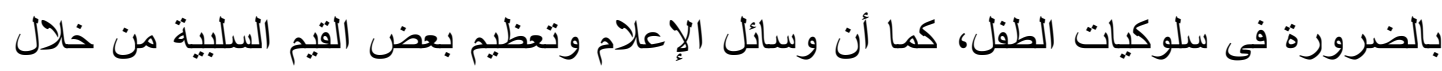
المسلسلات والأفلام، تؤثر إلى حد كبير على الأطفال وتزيد من إضطر اباتهم السلوكية .

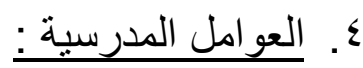

• تكسس عدة أطفال فى مقعد واحد وضيق الفصول وقلة الأجهزة والأدوات

$$
\text { و غير ها . }
$$

القصور فى شخصية بعض المعلمين والمعلمات : وتتمثل فى عدم القدرة على هلى

$$
\text { إقامة علاقات إنسانية مع الأطفال . }
$$

•القصور فى إعداد بعض المعلمين و المعلمات : ويظهر فى الإهمال وعدم منح

$$
\text { التدريب }
$$

وقد توصلت العديد من الدراسات إلى أن سلوكيات المعلم وطريقة تفاعله مع أطفال الروضة

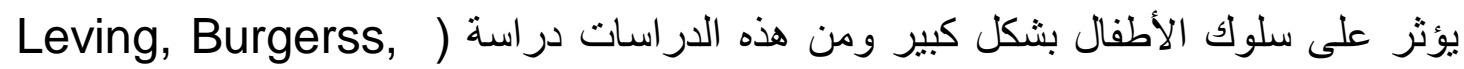

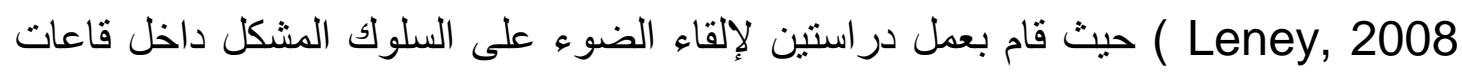
الروضة حيث أسفرت النتائج عن أن السلوك المشكل لدى الأطفال يرجع إلى توتر العاء العلاقة بين

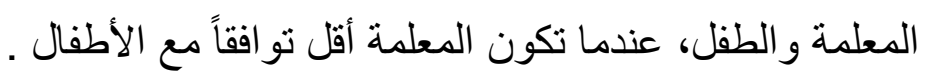

إلى جانب إضافة دراسة ( Buyse, et al, 2008 ) والتى إهتمت بالكثف عن أثر السلوك

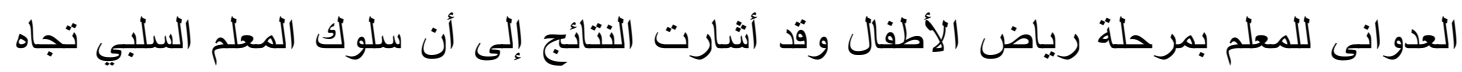

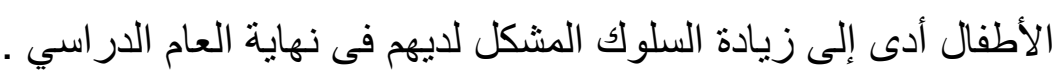
كما وتوصلت امانى عبد الرازق فى دراستها إلى عوامل أخري تتمثل فى : - القدوة السيئة وسوء فهم الطفل . ـ الحالة المز اجية للطفل .

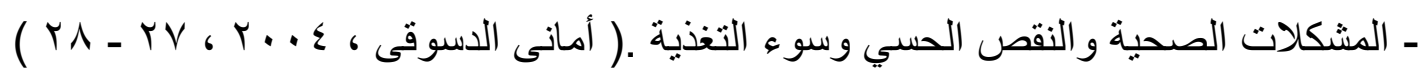
بالإضافة إلى ذللك قامت سلوى الماخذى ( V . . . ، ـ ـ 10 ) بتصنيف المشكلات السلوكية إلى 
1 - مشكلات إنفعالية : هى إضطر اب فى الإنفعال وتتمثل مظاهره فى الغيرة، ونوبات الغضب و العنف .

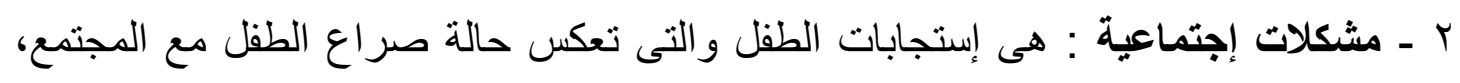
وتتمثل فى العدوان، الكذب، و العناد .

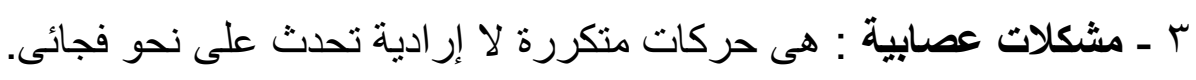

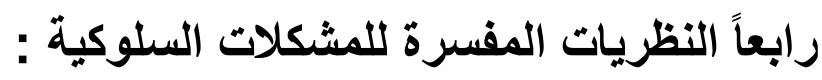

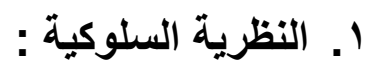

وفى هذه النظرية يكون المبدأ مبنى على فكرة أنه يمكننا ضبط السلوك و التنبؤ به إذا أمكننا

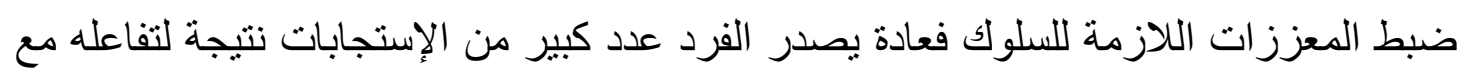

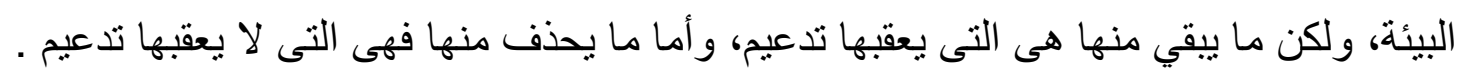

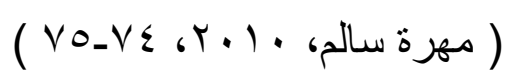
إلى جانب ذلك فأصحاب المدرسة السلوكية يؤكدوا على دراسة السلوك الظاهر والخبرة الخارجية والفعل ورد الفعل للناس، ويكون فهم الناس من خلال ملاحظة سلوكهم وليس دراسة

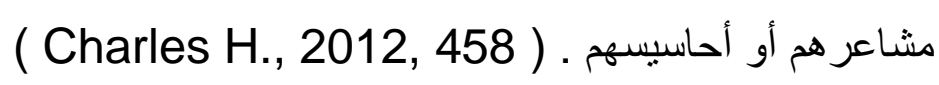
ويري أصحاب هذه النظرية أن السلوك السوى والغير سوى ما هو إلا سلوك متعلم، و عندما

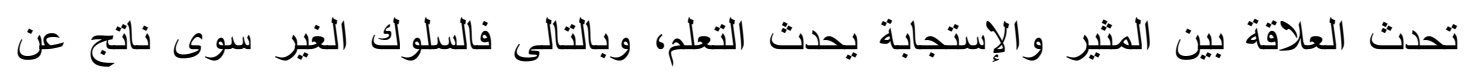

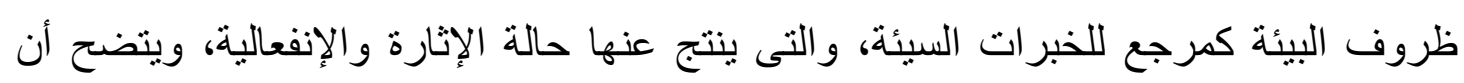
الطفل يتعلم الكثير من الإستجابات عن طريق ملاحظة النموذج المحتذى به وتلقى التعزيز

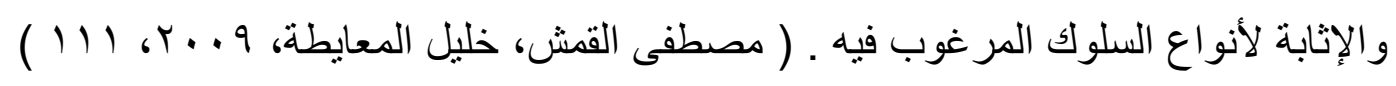

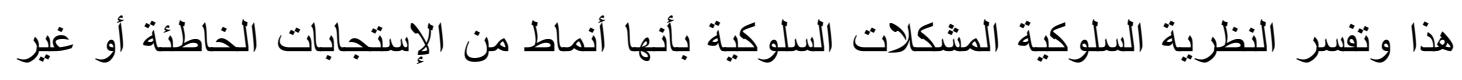

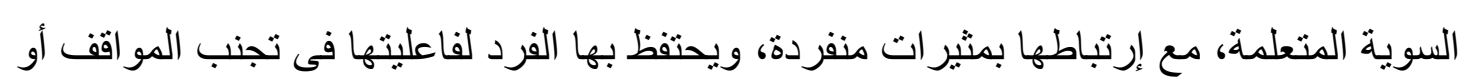

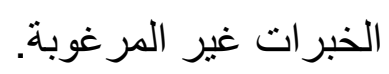

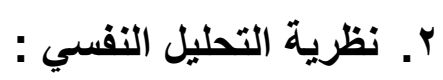

ويتبع أصحاب هذه النظرية فكرة أن التحليل النفسي يساعد الفرد على الإستبصار بسلوكه المرضى وتفسيره له كى يتمكن من التخفيف من الأسباب التى أدت إليه.

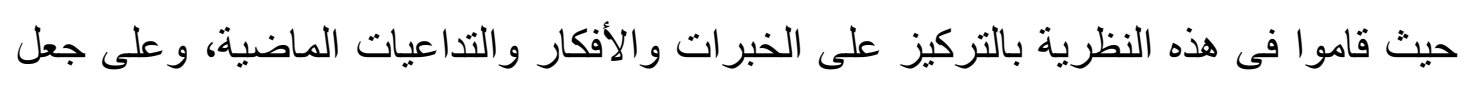

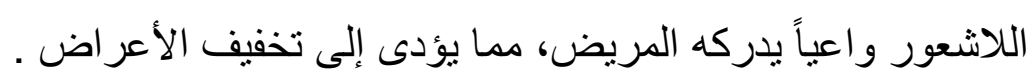

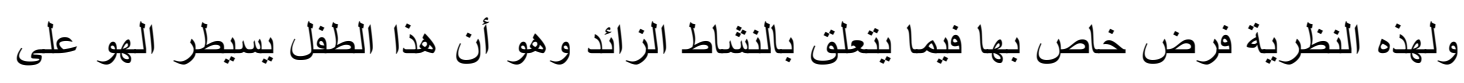

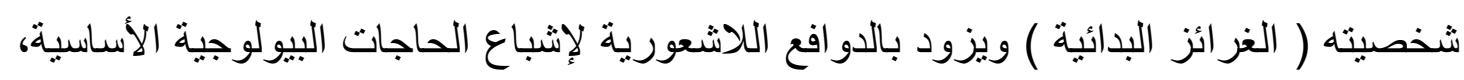


فالطفل ذو النشاط الزائد يعانى من أنا ضعيفة بسبب وجود عيب فى تكوين الأنا والأنا الأعلى

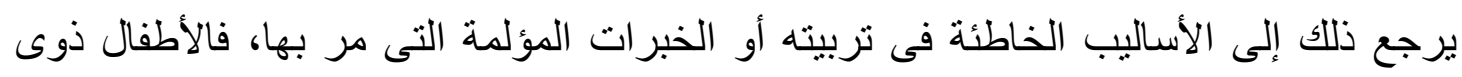

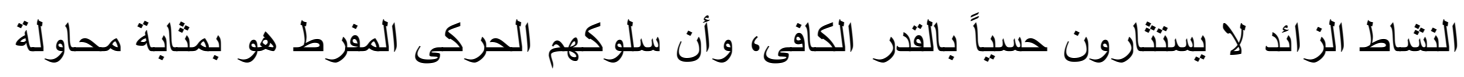

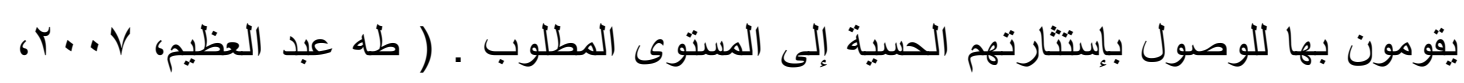
$(\Lambda T-\Lambda)$

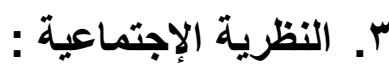

ويري أصحاب هذه النظرية أن سلوك الطفل يتمحور حول بيئته ومجاله الإجتماعى ونوعية

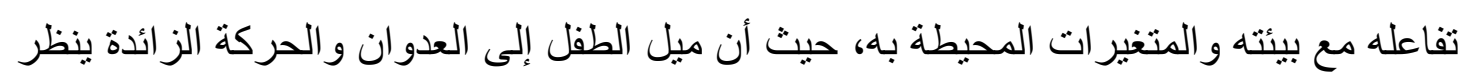

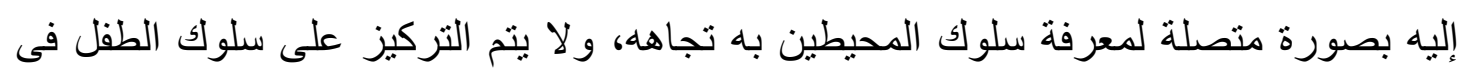

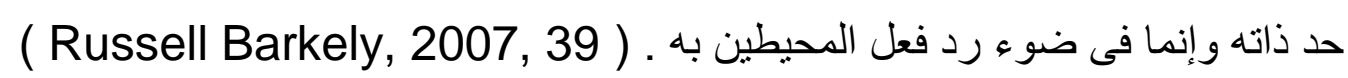
تحديد المشكلات السلوكية أولاًا التمرد : قد يكون الأطفال ذوى التمرد لايهم نمط من اللاتعاون، والسلوك العدوانى تجاه شخصيات السلطة والذى قد يتداخل مع الأداء الوظيفي اليومى للصغار وبشكل منظم وهؤلاء الأطفال غالباً ما يكونون سريعي التأثير و انتقاميين.

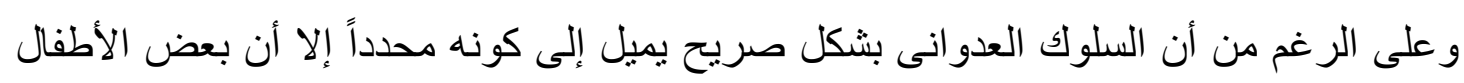

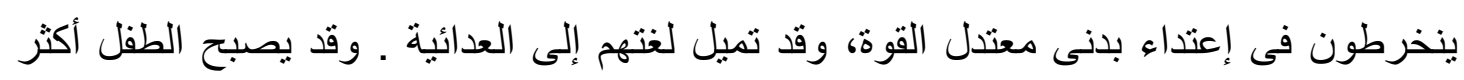

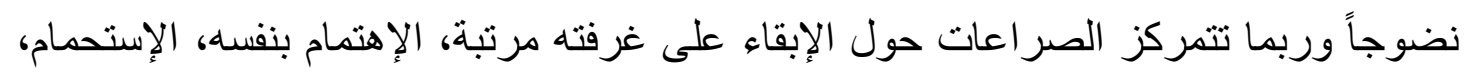

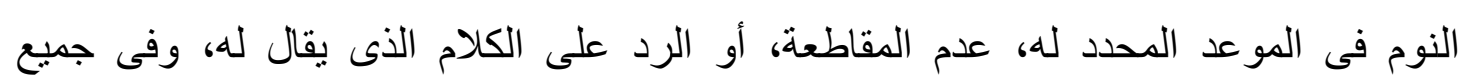

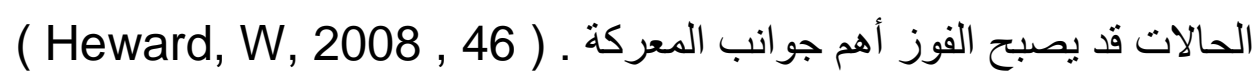

و على ذللك فإذا كانت سلوكيات الطفل المعارضة المستمرة تستمر لفترة لا تقل عن ستة أثنر وتظهر بوضوح لبيئة الأسرة والمؤسسة أو المدرسة، وقد تتصف سلوكيات الطفل المتمرد

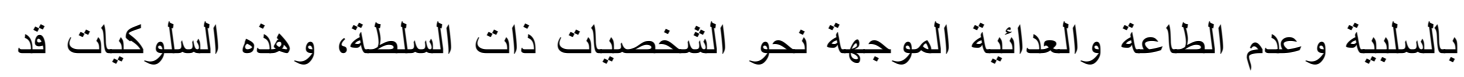
تتسبب فى أن يظهر الطفل بشكل منتظم ومستمر لهذه الأغراض، التى قد تتسم بالتقلبات المزاجية المتكررة، كمجادلة البالغين، صعوبة فى الإبقاء على الصداقات، مشكلات دراسية . 
ويعر العناد بأنه الرفض و عدم الإمتثال لما يطلب من الشخص، حيث يظهر عناده فى صورة الجدال والنقاش الذى لا ينتهى، أو رفض الأوامر التى توجه إليه من الكبار وكذلك عدم طاعته الإنه

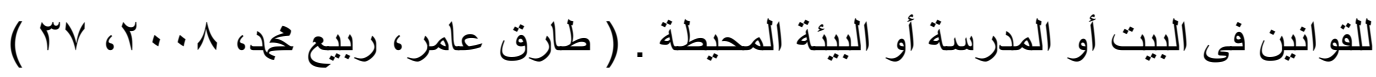

كما يعرف بأنه تعبير عن الرفض للقيام بعمل حتى وإن كان مفيداً أو الإنتهاء عن عمل ما وإن كان خاطئً، ودن مظاهره الإصرار و عدم التراجع حتى فى حالة الإكر اه ويبقي الطفل محتفظاً

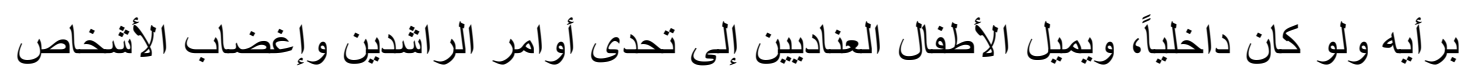
الأخرين عن عمد، ويميل هؤلاء الأطفال عادة إلى الغضب و الإنفعال بسهولة فى مواجهة أفعال الأخرين، ثم يلومون الأخرين على ما قاموا به أنفسه، ويوصفون بإنخفاض القدرة على تحمل

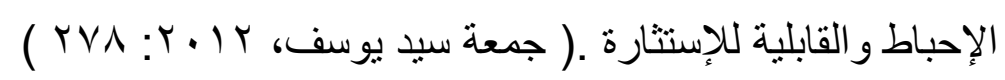

ومن المظاهر التى يمكن ملاحظتها معارضة الإرشادات والتعليمات أى لا يستجبب الطفل للمربية ويصر على موقفه، ومن العلامات العصبية حركات لا إرادية مثل هز الكتف أو الرأس وحركات الوجه ورمش العين أومص الأصابع وقرض الأظافر وشد الثعر وعض الثفتين .

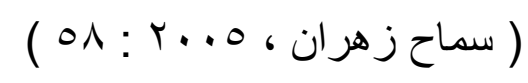

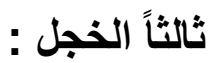

ويعرف بانه الثعور بعدم الإرتياح وصعوبة التعبير عن الذات والرغبة فى تجنب مواقف

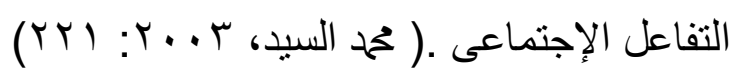
ونتيجة لردود أفعال الأخرين غالباً ما تؤدى إلى شعور هؤلاء الأطفال بالخجل غير المناسب، وسهولة الإرتباك وبدلاً من المخاطرة بإحتمال تعرضهم للحماقة، فإن هؤلاء الأطفال يحاولون تجنب عمل أى شىء جديد، أو الذهاب إلى أماكن جديدة أو مقابلة أناس جدد، دون صحبة أو حماية الوالدين لهم، ويفضلون الجلوس مزووين فى غرفة الدراسة بدلاً من إحتمال تعرضهم لقول المعلم بأن إجاباتهم خطأ، أو سماع تعليق سخيف من زملائهم . ( لجنة التعريب و الترجمة $\left(17: Y \cdot V_{6}\right.$

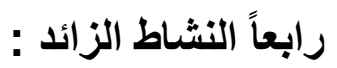


ويعرف النشاط الزائد على أنه مجموعة من الإضطر ابات التى تتميز بالبداية المبكرة وتتشابك

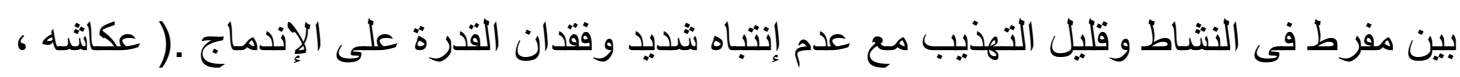
( V०9: r...

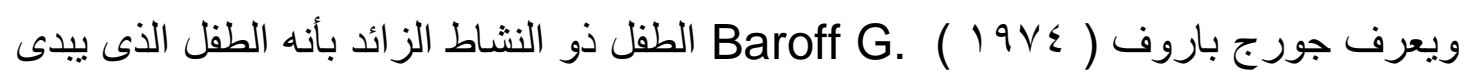
درجة من السلوك الحركى تفوق أقر انه ويتسم بتقلب المز اج وقلة الثبات ـ ( عبد الرحمن سليمان

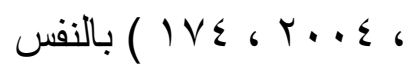
وتدنى مفهوم الذات و عدم القدرة على تحمل المسئولية، كما ينتابهم إحساس بعدم الرضا كما

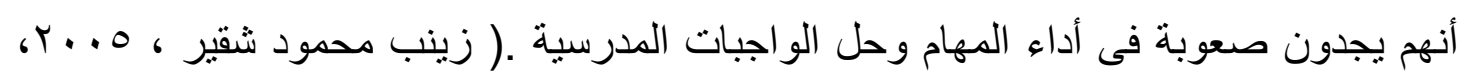
( rV ويظهر على الأطفال ذوى النشاط الحرك الزائد عدة سلوكيات غير سوية، منها العدوان

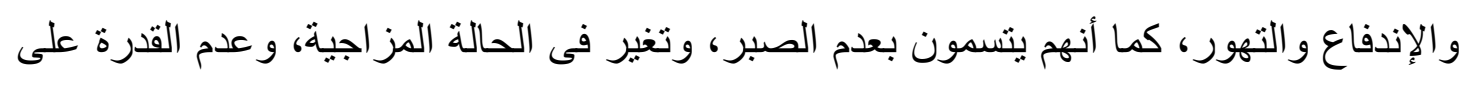

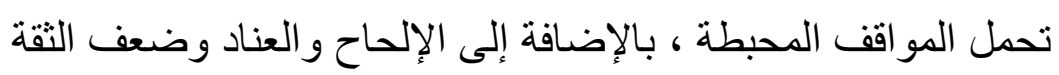

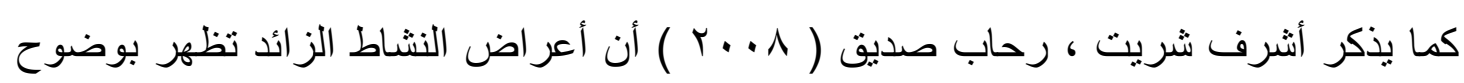

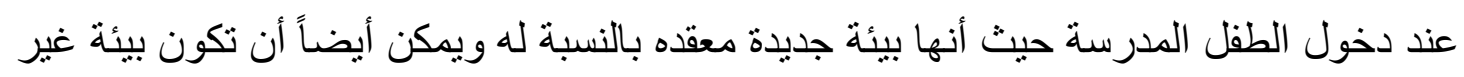

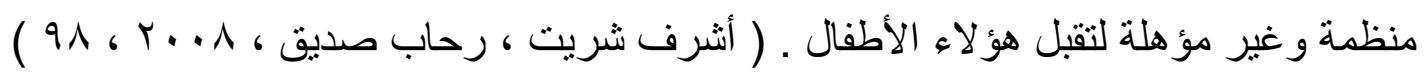

\section{إحتياجات الأطفال ذوى النشاط الزائد :}

(1) نوفير ثقافة غذائية تمكنه من إختيار أنواع التغذية ذات السعرات العات الحرارية المطلوبة لجسم الطفل فى هذه المرحلة.

r) يحتاج الطفل فى هذه المرحلة لمعرفة التغيرات التى سوف تطر أ على جسمه من خلال معرفة التغيير فى وظائف الغدد . معاج

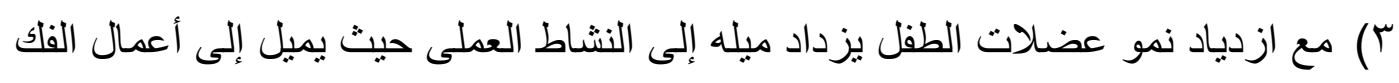
و التركيب و النجارة و النبات و أعمل الحياكة و التريكو.

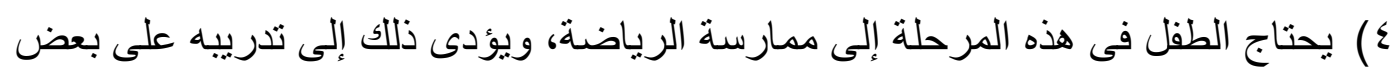

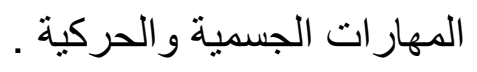

0) يحتاج الطفل إلى تنمية إدر اكه الجسمى : إدر الك الأعداد، إدر الك مفهوم الزمن، إدراك المسافات و الأوزان.

7) يحتاج الطفل إلى التدريب على مختلف الأنشطة الترويحية كالموسيقي والفنون 
V) يحتاج الطفل إلى تنمية وزيادة مفرداته اللغوية ونطق الكلمات والجمل بصورة سليمة، وذلك من خلال التشجيع المستمر على القراءة .

^) يحتاج الطفل إلى ممارسة الأنشطة المدرسية التى يتم من خلالها تحسن علاقاته الإجتماعية والإنفعالية، ويشعر بالمسئولية ويتم تقويم سلوكه الثخصى . 9) يحتاج الطفل إلى ممارسة العمل الجماعى أو تعويده على العمل الجماعى الذى من خلاله يلتزم بالمبادىء الأخلاقية الملموسة كالتعاون وإحتر ام الغير . ( حمح رفعت، ماهر

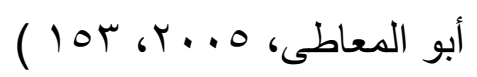
أعراض المشكلات السلوكية المترتبة على النشاط الزائد لاى جماعات الأطفال : ا ـ إظهار الطفل لسلوكين متناقضين فى أن واحد . r. عدم الإلتز ام بالمعايير والقيم الإجتماعية والخروج عنها فى السلوك .

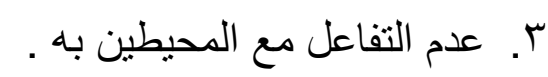
ع. عدم القدرة على تحمل الإحباط.

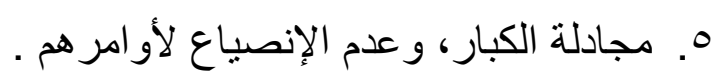
7. إيذاء المحيطين به سو اء إنسان أو حيوان .

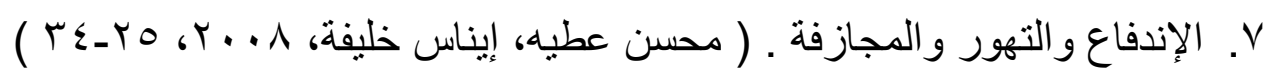
خامساً تشتت الإنتباه :

ويعرفه كمال سالم بأنه " قصر فى الإنتباه وهذا راجع إلى كثرة التشتت والإنشغالات بأثنياء خارجة عن موضوع الإنتباه، فالمثثير ات الجانبية لها تأثير المثيرات المباثرة "( كمال سالم سالم

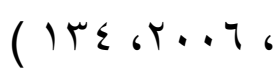
و يثير كلا من ( Barkley, R .A. \& Morris, F,2004, 449 ) إلى أن الأطفال الذين يعانون من تشتت الإنتباه لديهم قصور، مقارنة بالأطفال الأخرين من نفس العمر والذى يشمل العلاقات مع الكبار و عدم الإهتمام بمطالبهم إلى جانب الأداء المدرسى حيث ضعف التحصيل و الملل و السلوكيات العدوانية .

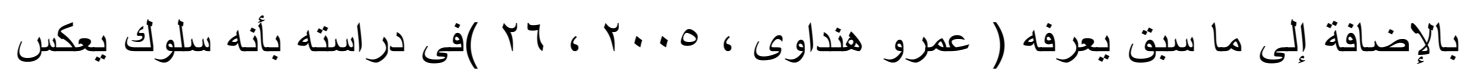
تشتت الإنتباه ويعتبر ذلك عقبة كبيرة للأطفال بالنسبة لنجاحهم الإجتماعى والتعليمي حيث يعتبره من المشكلات السلوكية المرتبطة بالطفولة. و هنالك بعض المبادىء التى يجب مر اعاتها عند التدريس لهذه الفئة : 
و هى كما أنشار إليها كمال زيتون بخفض طول المهمة وذللك عن طريق تجزئة مهمة التعليم إلى

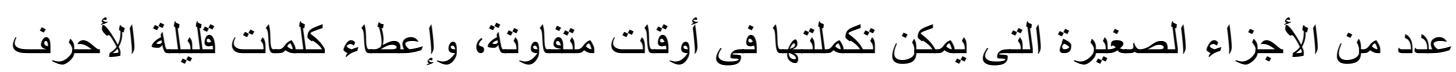

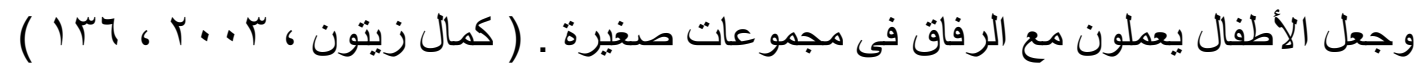

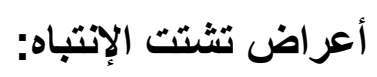

تضمن الاليل التشخيصي الإحصائى للإضطربات النفسية فى طبعته الخامسة ( ) DSM (IV,2014 المحكات التشخيصية لنتشت الإنتباه فيما يلي:

غالباً يفتل فى إعطاء إنتباه كامل للتفاصيل أو يقوم بعمل أخطاء ناجمة عن عدم العناية

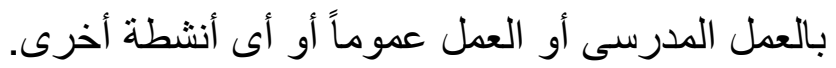
لايه صعوبة فى الإنتباه المستمر فى المهام أو أنشطة اللعب.

غالباً يبدو وكأنه لا يسمع عندما ينم التحدث إليه مبانثرة.

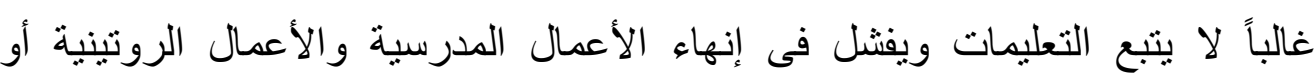
الو اجبات الخاصة.

غالباً يكون لايه صعوبة فى تنظيم المهام أو الأنشطة.

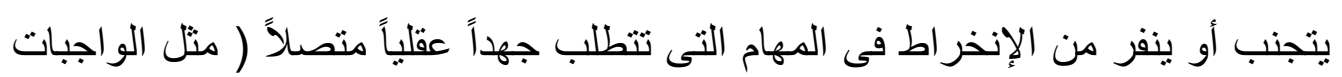
المدرسية أو العمال المنزلية ). غالباً يفقد الأشياء الضرورية لأداء المهام والأنشطة كاللعب والأغراض المدرسية العنال

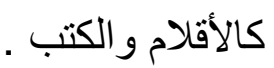
من السهل تشتت انتباهه بالمثير ات الخارجية. كثير النسيان بالأنشطة اليومية. غالباً يظهر تململاً بواسطة اليدين أو القدمين أو تحريك المقعد. يجري ويققز بشكل كبير فى المواقف التى تكون فيها تلك الأفعال غير ملائمة . دائم الحركة كما لو كان مدفو عاً بواسطة آلة أو ماكينة.

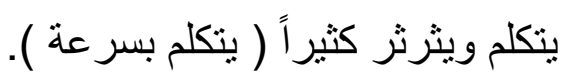
غالباً يندفع فى الإجابة قبل أن تكتمل الأسئلة. لايه صعوبة فى إنتظار دوره.

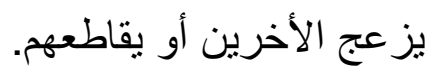
يتذخل فى الحديث أو اللعب. 


\section{ومن الأعراض الثانوية لتثتت الإتتباه}

ضعف العلاقة بالأخرين : حيث أنشار ( Barkley , 2006 ) أن الأطفال ذوى إضطر اب تشتت الإنتباه بظهرون ضعفاً فى طريقة التنظيم وهم غير بار عين فى التفاعلات الإجتماعية. سادساً القلق : وفى بعض الأوقات قد يظهر القلق الذى تم تعميمه لدى بعض الأطفال فى صورة توقع أى شىء

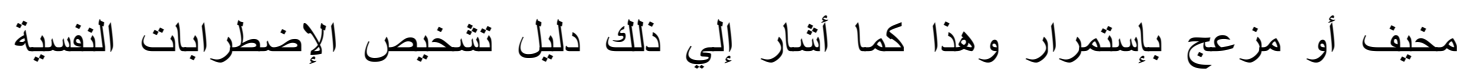

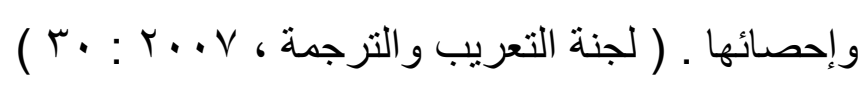

و أحياناً قد تتحول بعض خصائص الثخصية مثل الجمود و الحساسية الزائدة و الخجل و التشاؤم

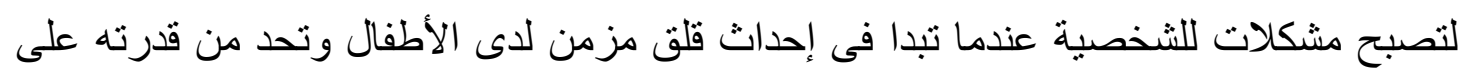

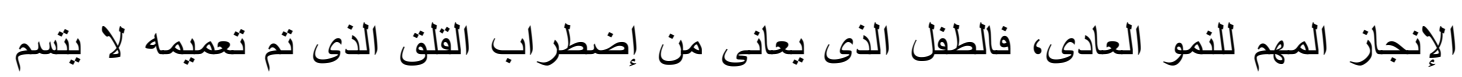
بالجبن فحسب، وإنما يعانى من خوف يثل حركته عن مواجهة متطلبات التفاعلات الإنسانية

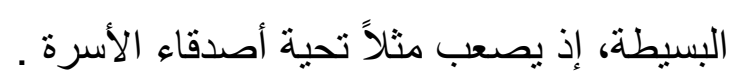
إضافة إلى ما تم عرضه من تحليل لبعض المشكلات السلوكية المختلفة الثائعة بين الأطفال

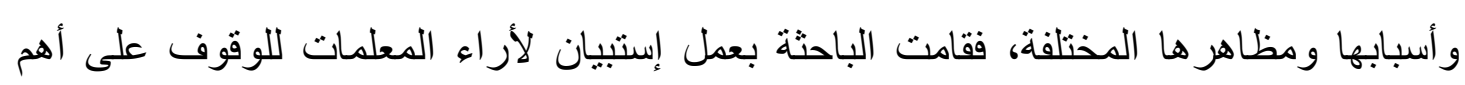
السلوكيات الثائعة بين الأطفال ومدى إستمراريتها

\begin{tabular}{|c|c|c|c|c|}
\hline ע & أحياناً & دائماً & العبارات - - مات & مسلسل \\
\hline & & & يميل إلى الجلوس بمفرده & 1 \\
\hline & & & يتحدث بدون استئذان & $r$ \\
\hline & & & يستخدم ألفاظ غير مهذبة & $r$ \\
\hline & & & يحكى قصص غير حقيقية لم تحدث & $\varepsilon$ \\
\hline & & & يقضم أظافره & o \\
\hline & & & يتردد فى فعل الأثياء والقرارات & 7 \\
\hline & & & ينسب أخطائه للغير & $\mathrm{v}$ \\
\hline & & & متقلب المزاج & $\Lambda$ \\
\hline & & & يميل للجلوس منفرد فى المناسابات & 9 \\
\hline & & & يندفع في تصرفاته & 1. \\
\hline & & & يعمل عكس ما يطلب منه & 11 \\
\hline & & & يرفض الإشتراك والتعاون فى الأنشطة الجماعية & Ir \\
\hline & & & يشعر بقلق & ir \\
\hline & & & يتلعثم فى الكلام امام الجماعة & $1 \leq$ \\
\hline & & & يرتبك بسهولة & 10 \\
\hline & & & يرفض تكوين أصدقاء جدد & 17 \\
\hline & & & يرفض الذهاب للروضة & IV \\
\hline
\end{tabular}




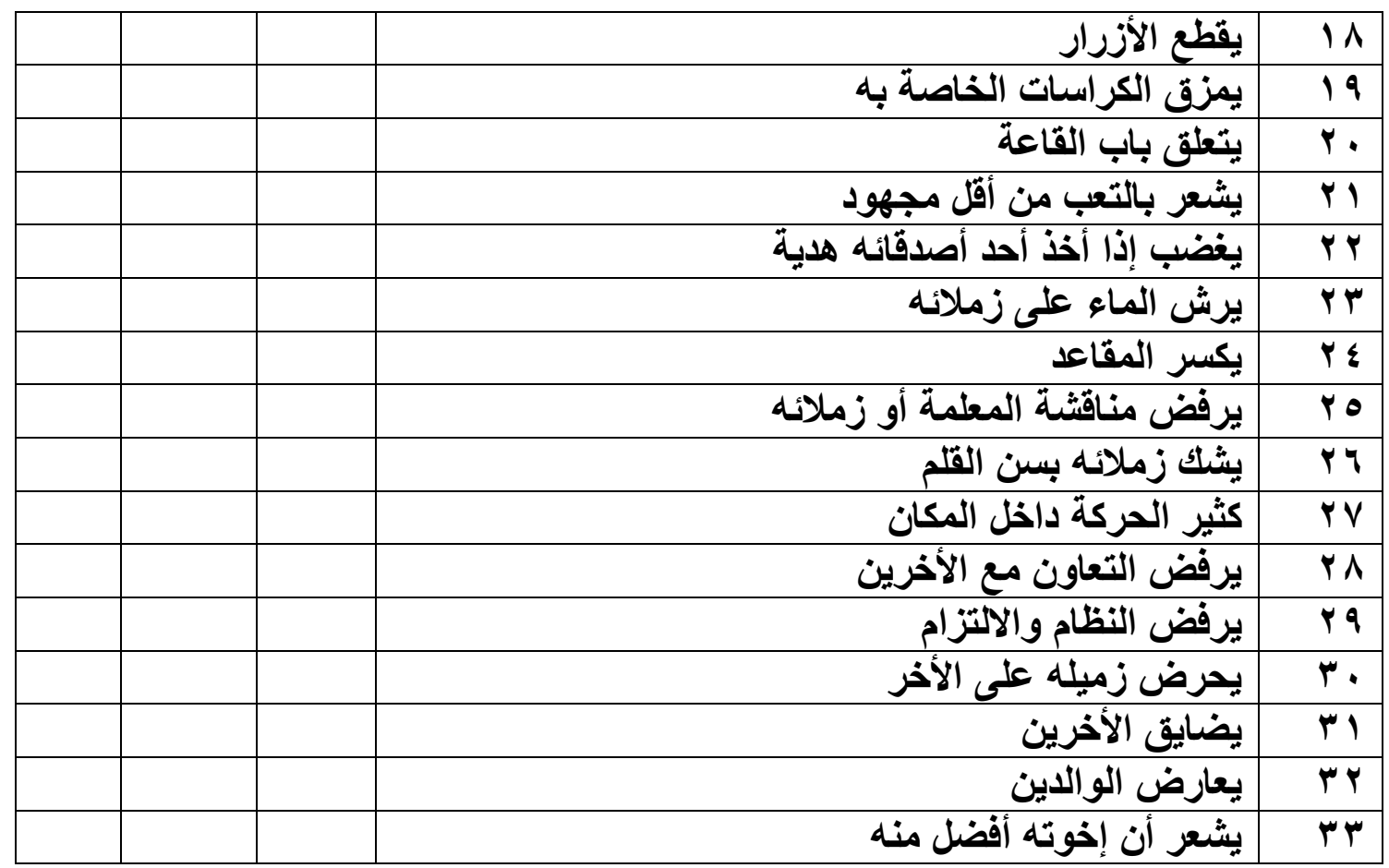

\section{النتائج والتوصيات}

و إستناداً إلى ما تقدم عرضه حول المشكلات السلوكية المختلفة وأثر ها البالغ على الأطفال وبعد جمع وتحليل نتائج إستبيان أراء المعلمات للوقوف على أهم المشكلات السلوكية الثائعة و الملحوظة بين الأطفال فى مرحلة الطفولة المبكرة تبين للباحثة تكرار المشكلات السلوكية

$$
\text { و المتمثلة فى ( القلق - التمرد - العناد - تشتت الإنتباه والحركة الزائدة ) }
$$

و عليه فتري الباحثة أنه من الضرورى الإهتمام بالمشكلات السلوكية والتعرف عليها وتعديلها فى مرحلة الطفولة المبكرة مما لها من كبير الأثر فى تكوين شخصية الطفل المستقبلية وأن بداية المشكلات السلوكية المختلفة كالنشاط الزائد وعدم التركيز والعناد والقلق وغيرهم يمكن ملاحظتها فى مرحلة الطفولة المبكرة حيث أنه كلما طالت الفترة التى يعانى فيها الأطفال من هذه المشكلات كلما أصبح علاجها أكثر صعوبة . 


\section{توصيات الدراسة}

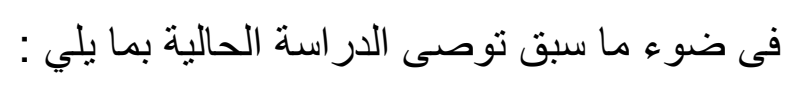

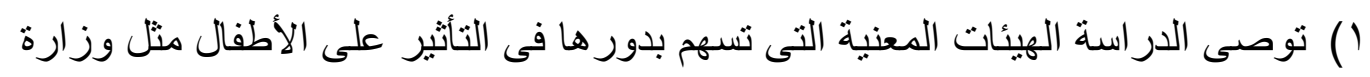

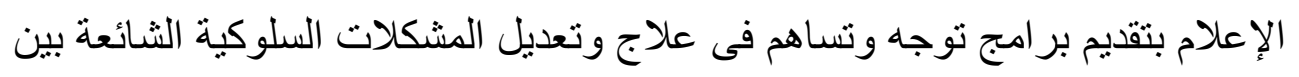
الأطفال . الإل

r) توصى الدراسة الهيئات التعليمية و المسئولة عن مرحلة الطفولة المبكرة بتفعيل منهج

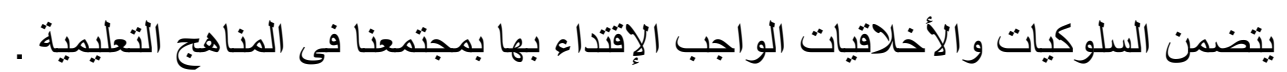

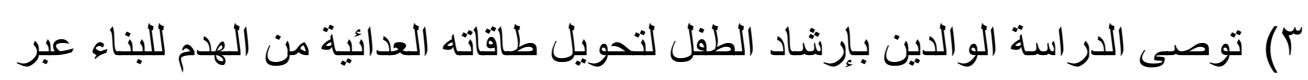

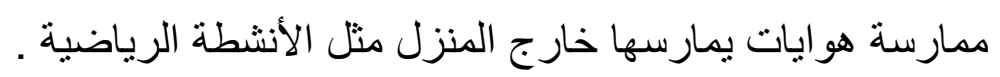

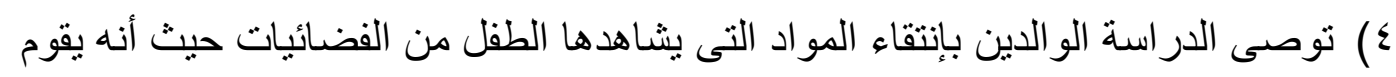

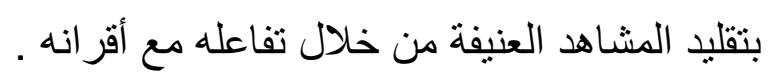

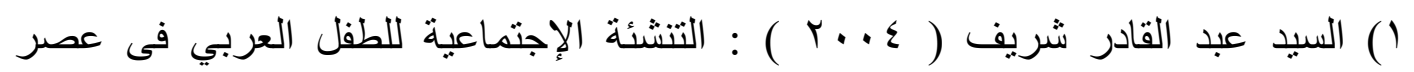
العولمة، طץ ، دار الفكر العربي، القاهرة .

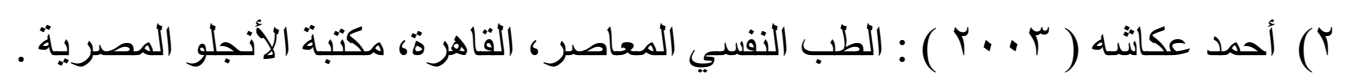

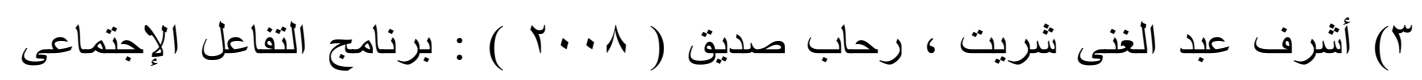

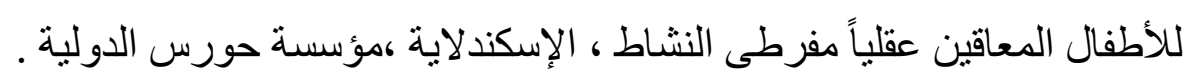

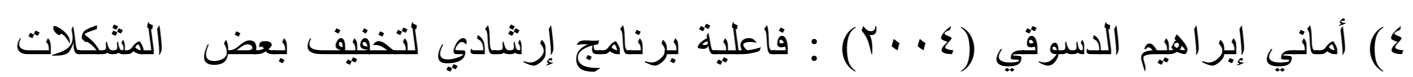

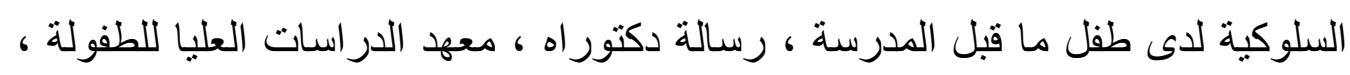

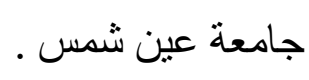

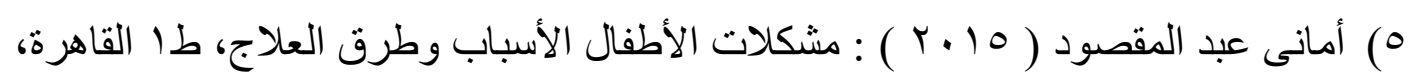
مكتبة الأنجلو المصرية . ماندي

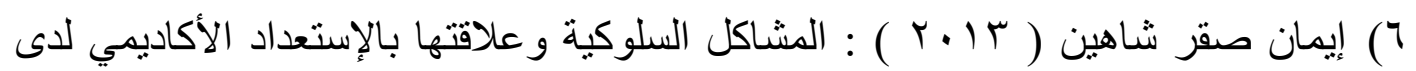

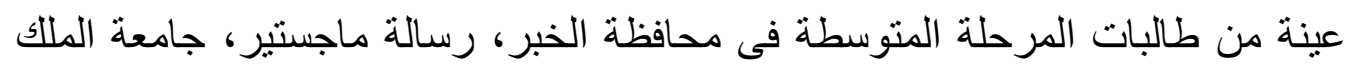

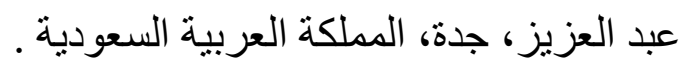


V باولو سيرجيو ، ترجمة مالك قطينة ( V . . P ) : التقرير العالمى بشأن العنف ضد الأطفال، منظمة الأمم المتحدة . لبرئ

^) بطرس حافظ بطرس ( ع ( ب ) ) طرق تدريس الطلبة المضطربين سلوكياً و إنفعالياً،

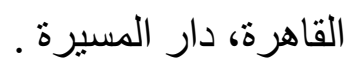

9) جمال عطيه فايد ( V . . . P ) : العلاقة بين أساليب المعاملة الوالدية كمتغير وسيط بين الخصائص المزاجية والمشكلات السلوكية لدى أطفال الروضة، المؤتمر السنوى الرابع عشر لمركز الإرشاد النفسي، جامعة عين شمس .

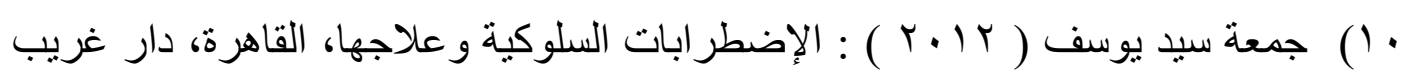
للطباعة و النشر .

1 (1) رافد الحريري، زهرة بن رجب ( ^ . . r ) :المشكلات السلوكية النفسية والتربوية لتلاميذ المرحلة الإبتدائية، دار المناهج للنشر و التوزيع، عمان .

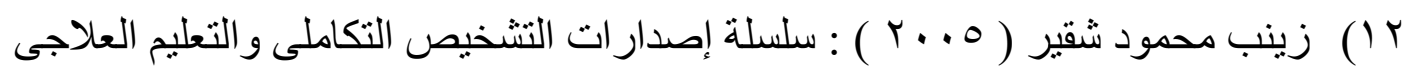
لغير العاديين ( المعاق جسمياً، حركيا، إنفعالياً ) المجلد الخامس، القاهرة، مكتبة النهضة المصرية.

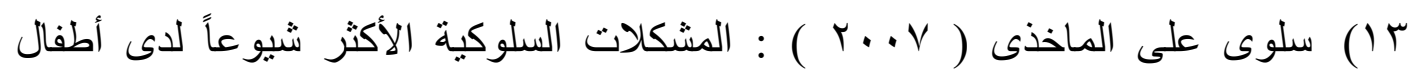
الروضة وعلاقتها بالمناخ الأسري بالجمهورية اليمنية، رسالة دكتور اة، معهد الدر اسات العليا للطفولة، جامعة عين شمس .

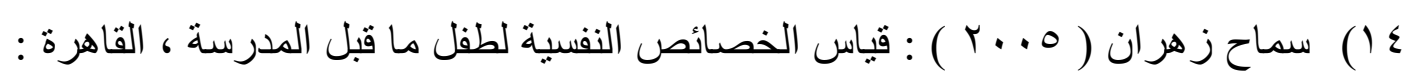
دار الفكر العربى .

1) سهير التوني (T + . ץ) : فاعلية برنامج في الأنشطة الفنية البدوية في خفض بعض المشكلات السلوكية لاى الأطفال الصم ، رسالة ماجستير غير منشورة ، كلية التربية ـ جامعة المنيا.

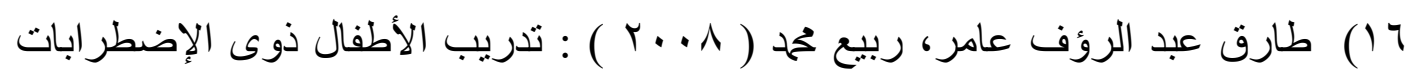
السلوكية، عمان، دار الفكر .

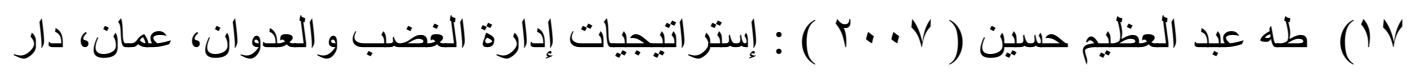
الفكر . 


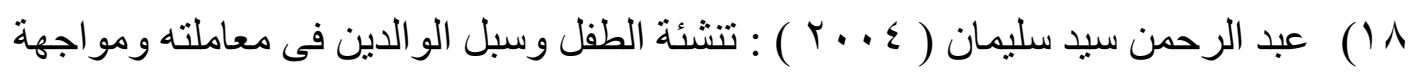
مشكلاته ، القاهرة ، دار الفكر العربي .

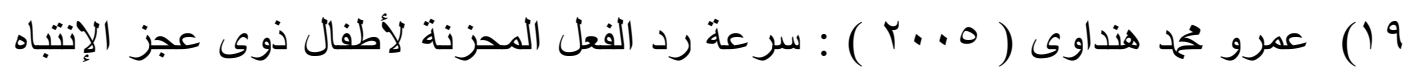
و النشاط الزائد. مجلة العلوم التربوية و النفسية. المجلد السابع. العدد الأول ( جr )

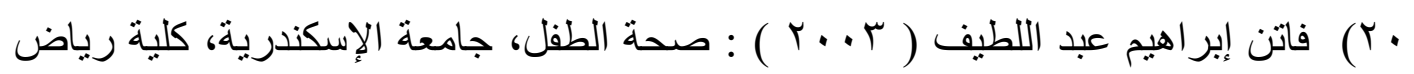
الأطفال.

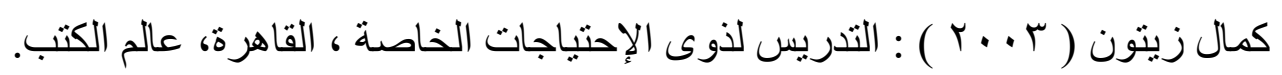

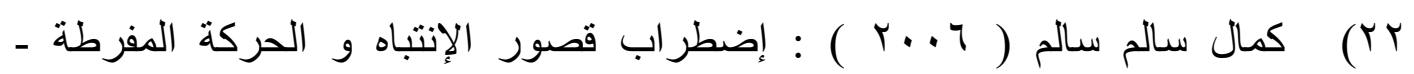
خصائصها وأسبابها ـ أساليب علاجها ـ العين : دار الكتاب الجامعى .

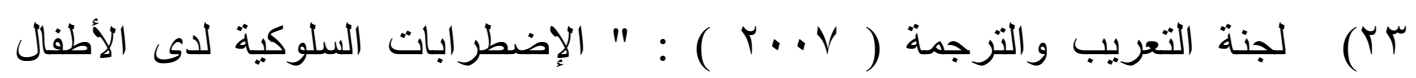
و المر اهقين " ، طا ، الإمارات العربية المتحدة ، دار الكتاب الجامعى .تعليم الأطفال الدر اما ، المسرح، الفنون التشكيلية، الموسيقى ، عمان ، دار صفاء للتوزيع .

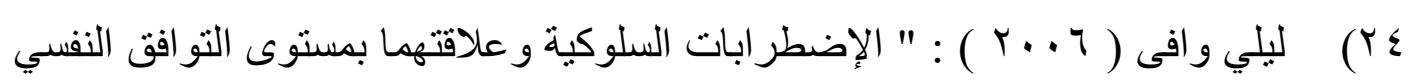
لاى الأطفال الصم و المكفوفين ، رسالة ماجستير غير منشورة ، كلية التربية ، الجامعة الإسلامية ، غزة.

OY) محسن على عطيه، إيناس خليفة خليفة( A ... ) : المشكلات السوكية لأطفال الروضة، عمان، دار المناهج للنشر و التوزيع .

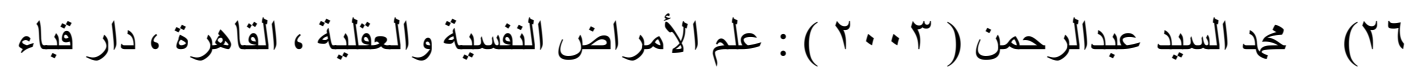
للطباعة .

(YV

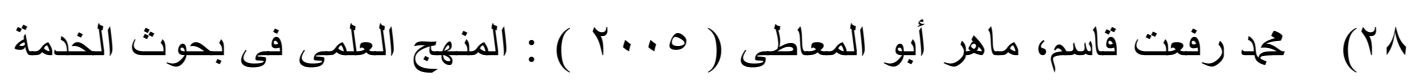
الإجتماعية، أسس نظرية ونماذج تطبيقية، القاهرة، مكتبة زهر اء الثرق. محمود أبو دف ( 7 . . r ) : در اسات فى الفكر التربوى الإسلامى ، طا .

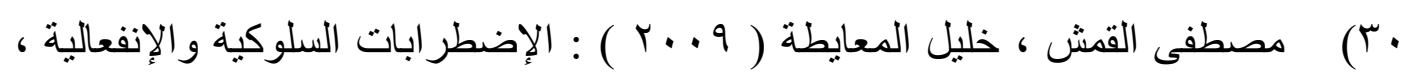

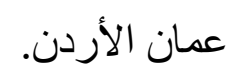




$$
\begin{aligned}
& \text { منال رشيد ( • • ب ) : الظواهر السلوكية غير المرغوبة لدى الأطفال، عمان، دار } \\
& \text { صفاء للنشر و التوزيع . الت }
\end{aligned}
$$

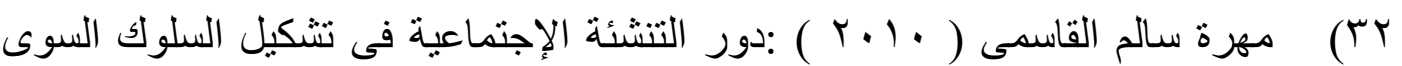

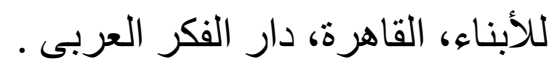

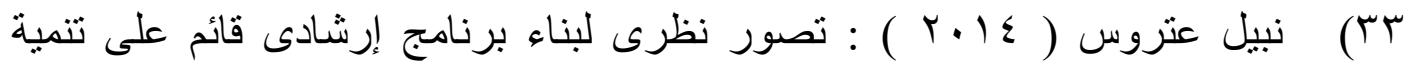
المهارات الإجتماعية لدى أطفال ما قبل المدرسة من ذوى المشكلات السلوكية، مجلة

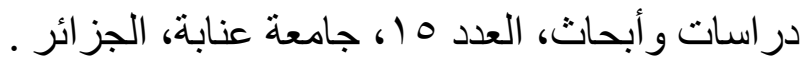

34) Barkley R.A ( 2006 ) : Attention Deficit Hyperactivity Disorder, A clinical work book 3rd ( ED ), New York, Guilford publishers.

35) Briere,J \& Elliot, D.( 2003 ) : Prevalence and Psychological sequelae of self reported childhood physical and sexual abuse in a general population sample of men and women, Child Abuse \& Neglect, The International Journal, 27 ( 10 ), 1205- 1222.

36) Buyse, E; Verschueren, K; Doumen,S; Van Damme, J \& Maes, F( 2008 ) : Classroom Problem Behavior and Teacher Relationships in Kindergarten, The Moderating Role of Classroom Climate, Journal of School Psychology, V46, N4, P367-391 Aug .

37) Charles H. ( 2012 ) : Social Work with Groups a Comprehensive Work text, 8 Edition,Australia,Brooks Cole, P458.

38) Diagnostic and Statistical Manual of Mental Disorders ( 2014 ) :FifthEdition.

39) Erin M. Ingoldsby, Daniel S. Shaw, Emily Winslow, Michael Schonberg, Miles Gilliom, Michael M. Criss , ( 2006 ) : Neighborhood Disadvantage, Parent-Child Conflict, Neighborhood Peer Relationships, and Early Antisocial Behavior Problem Trajectories, Journal of Abnormal Child Psychology, Volume 34, Issue 3 
40) Heward,W. ( 2008 ) : American Academy of Child Adolescent Psychiatry, The British Journal of Education Psychology, P46 .

41) Leving, L; Burgess, S \& Laney, C ( 2008 ) : Effects of Discrete Emotions on Young Children Suggestibility, Journal Articles; Reports Research Developmental Psychology, V44,N3,P681-694 May .

42) Mireault. G; Rooney, S; Kouwenhoven, K; Hannan, C ( 2008 ) : Oppositional Behavior and Axiety in Boys and Girls, A Cross Sectional Study in Two Community Samples, Child Psychiarty and Human Development, V39, N4, P519-527 .

43) Riggin, M.; Brausch,A. and Montgomery,B. ( 2007 ) : A metaanalytic investigation of therapy modality outcomes for sexually abused children and adolescents, An exploratory study, Child abuse \& Neglect, The International Journal,31 ( 2 ): 125 - 141 .

44) Russell Barkley ( 2007 ) : Psychosocial Treatments for Attention Deficit Hyperactivity in Children,Journal of Clinical Psychiatry, Vol 63, P 39.

45) Shivers,M.( 2003 ) : Maternal depression, parenting style and behavior problems in preschool children, Dissertation Abstracts International,VOL.65( 04-B).P.106.

46) Watts, K. S. ( 2015 ) : The Effectiveness of a Social Story Intervention in Decreasing Behavior Disorders in Young Learning Disabled Children. PHD Thesis, Ohio State University . 